\title{
Influence of Track Changes on the Poleward Shift of LMI Location of Western North Pacific Tropical Cyclones
}

\author{
RUIFANG WANG \\ Pacific Typhoon Research Center, and Key Laboratory of Meteorological Disaster of the Ministry of Education, Nanjing University \\ of Information Science and Technology, Nanjing, China \\ LIGUANG WU \\ Department of Atmospheric and Oceanic Sciences, and Institute of Atmospheric Sciences, Fudan University, Shanghai, China
}

(Manuscript received 12 December 2018, in final form 1 September 2019)

\begin{abstract}
The annual mean latitude at which tropical cyclones (TCs) reach their lifetime maximum intensity (LMI) over the western North Pacific Ocean basin has shifted northward since the early 1980s, and it is suggested that the shift is due to the northward migration of the mean TC formation location. In this study, the TC intensity is simulated with an intensity model to assess the historical records of TC intensity. During the period 19802015 , the simulated poleward trend in the mean latitude of LMI is $0.44^{\circ}(10 \mathrm{yr})^{-1}$, which agrees well with the one $\left[0.48^{\circ}(10 \mathrm{yr})^{-1}\right]$ derived from the Joint Typhoon Warning Center (JTWC) dataset. This suggests that the observed poleward trend in the mean latitude of LMI is physically consistent with changes in the large-scale ocean-atmosphere environment and TC track. This study also demonstrates that the temporal change in the environmental parameters (sea surface temperature, outflow temperature, vertical wind shear, and ocean mixed layer depth) has little influence on the observed shift of the mean LMI latitude. The poleward migration of the mean LMI latitude is mainly due to the TC track shift, which results primarily from the change in the large-scale steering flow.
\end{abstract}

\section{Introduction}

The annual mean latitude where tropical cyclones (TCs) reach their lifetime maximum intensity (LMI) over the western North Pacific basin (WNP) has shifted northward since the early 1980s, and the poleward shift is possibly linked to the anthropogenic influence on TC activity (Kossin et al. 2014; Moon et al. 2015; Kossin et al. 2016; Zhan and Wang 2017; Daloz and Camargo 2018; Song and Klotzbach 2018). A few studies found that the shift in the mean LMI latitude is consistent with the northward migration of the mean TC formation location over the past three decades (Kossin et al. 2014, 2016; Zhan and Wang 2017; Daloz and Camargo 2018; Song and Klotzbach 2018). However, the migration of the mean formation location does not necessarily result in the shift of the LMI latitude. In principle, the LMI latitude of a TC also depends on its subsequent track and

\footnotetext{
Corresponding author: Prof. Liguang Wu, liguangwu@fudan. edu.cn
}

the environment that the TC moves through. So far, the mechanism responsible for the shift of the mean LMI latitude is not fully understood.

Although Kossin et al. (2014) argued that the measurement of the LMI latitude should be less uncertain than the historical records of TC intensity, in fact there are substantial differences in the change of the mean LMI latitude among various TC datasets in the WNP basin. The poleward trend derived from the International Best Track Archive for Climate Stewardship (IBTrACS) is $37 \mathrm{~km}(10 \mathrm{yr})^{-1}$ over the period $1982-$ 2012, while the dataset of TC intensity from Kossin et al. (2013) exhibits a rate of $105 \mathrm{~km}(10 \mathrm{yr})^{-1}$ during the period 1982-2009 (Kossin et al. 2014). The latter is about a threefold of the former. Zhan and Wang (2017) found that the poleward trends in the mean LMI latitude over the WNP range from $0.34^{\circ}$ to $0.58^{\circ}(10 \mathrm{yr})^{-1}$ in the best-track datasets from three distinct agencies (the Joint Typhoon Warning Center, the Japan Meteorological Agency, and the China Meteorological Administration) during the period 1980-2016. Given the 
relatively small uncertainty in locating TC centers after the satellite era, the different trends in the mean LMI latitude may be mainly due to the uncertainty in the historical records of TC intensity (Landsea et al. 2006; Kamahori et al. 2006; Wu et al. 2006; Song et al. 2010; Klotzbach and Landsea 2015). The uncertainty in TC intensity has to be addressed when we quantify the contributions of various factors to the observed poleward shift of the mean LMI latitude.

It has been found that the TC intensity model that was used in Emanuel et al. (2008) is an effective tool to assess the uncertainty in the observed records of TC intensity (Wu and Zhao 2012; Wu et al. 2018). The TC intensity model is coupled with a one-dimensional ocean model to include the influence of the TC-induced ocean cooling. Wu and Zhao (2012) used the intensity model to assess the reliability of the TC intensity in the best-track datasets from the three agencies and found that the derived evolution of TC intensity is dynamically consistent with that in the Joint Typhoon Warning Center (JTWC) best-track dataset. Recently, Wu et al. (2018) conducted numerical experiments with the coupled intensity model and demonstrated that the increase of the proportion of intense typhoons (categories 4 and 5) during 1980-2015 is consistent with the corresponding changes in the ocean-atmosphere environment. They further suggest that the deepening of the ocean mixed layer resulting from its temporal variations and track shifts plays a dominant role in the observed increase of the proportion of intense typhoons.

The objective of this study is to quantify the contributions of various factors including changes in the large-scale environmental parameters and TC tracks to the observed shift of the basinwide mean latitude of LMI. Following Wu et al. (2018), the numerical experiments in this study are conducted with the coupled model. We first demonstrate that the model can well simulate the observed shift of the basinwide mean latitude of LMI and then sensitivity experiments are run to identify the contributions of the temporal changes in large-scale environmental parameters and the shift of TC prevailing tracks.

\section{Data}

The TC best-track data are from the JTWC because Wu and Zhao (2012) suggested that the intensity records in the JTWC best-track dataset are best correlated with the simulated intensity since the 1970s. It is well known that major environmental parameters controlling TC intensity are the underlying sea surface temperature (SST), the outflow temperature (OFT), vertical wind shear (VWS), and the ocean mixed layer depth (MLD). Based on the maximum potential intensity (MPI) theory, the environmental SST and OFT establish theoretically an upper limit of TC intensity (Emanuel 1987, 1999), while VWS can inhibit a TC from achieving its MPI (Gray 1968; Frank and Ritchie 2001; Emanuel et al. 2004). Moreover, the strong TC circulation can induce sea surface cooling and the magnitude of the cooling depends on the ocean MLD. In general, the shallower the MLD, the stronger the resulting sea surface cooling (Bender and Ginis 2000; Shay et al. 2000; Wu et al. 2005).

The atmosphere-ocean environmental parameters are derived from the following datasets. The SST data are from the National Oceanic and Atmospheric Administration (NOAA) extended reconstructed SST (ERSST, version 4) data with $2^{\circ}$ latitude by $2^{\circ}$ longitude resolution (Huang et al.2015). The dataset of the ocean MLD is from the National Environmental Prediction Center (NCEP) Global Ocean Data Assimilation System (GODAS) with a resolution of $1^{\circ}$ by $1^{\circ}$, which is enhanced to $1 / 3^{\circ}$ in the north-south direction within $10^{\circ}$ of the equator (Saha et al. 2006). The MLD data are available for the period 1980-2015. The TC outflow temperature is a parameter for the thermodynamic control of TC intensity (Emanuel et al. 2013). In this study, the outflow temperature of TCs is represented by the tropopause temperature, which is from the NCEP-National Center for Atmospheric Research Reanalysis (NCEP-NCAR; $2.5^{\circ}$ latitude $\times 2.5^{\circ}$ longitude with 17 vertical levels; Kalnay et al. 1996).

The VWS between 200 and $850 \mathrm{hPa}$ and large-scale steering flow are derived from an ensemble of six modern reanalysis datasets: 1$) \mathrm{NCEP}-\mathrm{NCAR}\left(2.5^{\circ}\right.$ latitude $\times 2.5^{\circ}$ longitude with 17 vertical levels; Kalnay et al. 1996), 2) the European Centre for Medium-Range Weather Forecasts interim reanalysis (ERA-Interim; $1.5^{\circ}$ latitude $\times 1.5^{\circ}$ longitude with 37 vertical levels; Dee et al. 2011), 3) the Japanese 55-year Reanalysis (JRA-55; $1.25^{\circ}$ latitude $\times 1.25^{\circ}$ longitude with 37 vertical levels; Kobayashi et al. 2015), 4) the National Aeronautics and Space Administration Modern-Era Reanalysis for Research and Applications (MERRA; $12^{\circ}$ latitude $\times 2 / 3^{\circ}$ longitude with 42 vertical levels; Rienecker et al. 2011), 5) the NCEP-U.S. Department of Energy second reanalysis (NCEP-DOE; $2.5^{\circ}$ latitude $\times 2.5^{\circ}$ longitude with 17 vertical levels; Kanamitsu et al. 2002), and 6) the NCEP Climate Forecast System Reanalysis (CFSR; $0.5^{\circ}$ latitude $\times 0.5^{\circ}$ longitude with 37 levels; Saha et al. 2010). The large-scale steering flow is defined as the pressureweighted mean flow from 850 to $300 \mathrm{hPa}$ (Wu and Wang 2004).

\section{Experimental design}

Two types of numerical experiments are conducted in this study. The first type is conducted with the TC 
intensity model. The input for the intensity model includes the observed TC tracks and four environmental parameters (SST, OFT, VWS, and MLD). For each TC, the model is initialized with a warm-core cyclonic vortex with a maximum wind speed of $21 \mathrm{~m} \mathrm{~s}^{-1}$. The environmental relative humidity in the boundary layer and in the middle troposphere is $80 \%$ and $45 \%$, respectively. The Coriolis parameter holds constant at $21^{\circ} \mathrm{N}$. The other parameters for the initial vortex are taken from Emanuel et al. (2008). The intensity model is integrated for each observed TC and the model TC moves along the observed tracks in the model.

Following Kossin et al. (2016), our simulation mainly covers TC season (July-November) during the period 1980-2015. Table 1 shows the description of the numerical experiments. We first design two experiments to examine the capability of the coupled intensity model. In IE1, the monthly mean environmental parameters are used for each year. IE2 is the same as IE1, but the environmental parameters are further averaged over the two periods 1980-97 and 1998-2015 and the model is run with the averaged environmental parameters in the first and second periods, respectively. The division of the two periods can facilitate our analysis of the contributions of the temporal change in the large-scale environment and the TC prevailing track changes. Statistically there is an abrupt change in the mean LMI latitude around 1997.

Experiments IE3 and IE4 are designed to separate the contribution of large-scale environmental parameters (SST, OFT, VWS, and MLD) from that of the TC track change. IE3 is the same as IE2, but the tracks of 397 TCs observed during the first period are used in both the first and second periods. IE4 is the same as IE3, but the observed tracks (316 TCs) in the second period are used. The simulated latitude differences between the two periods arise only from the influence of the environmental parameters, while the latitude difference during the same period between IE3 and IE4 is only due to the track change.

The second type of numerical experiments are conducted with a TC track model, which is adopted from Wu and Wang (2004). A TC in the model is taken as a point vortex and moves with the translation velocity including the large-scale steering and mean beta drift. The large-scale steering flow is defined in this study as the mean flow between 850 and $300 \mathrm{hPa}$. The climatologic mean beta drift is calculated over the period 1980-2015. Moreover, random synoptic-scale disturbances are added in the translation velocity to consider the possible effect of synoptic-scale systems on TC motion. The integration of the track model is terminated when the simulated TC track is not within the selected domain $\left(0^{\circ}-40^{\circ} \mathrm{N}, 100^{\circ} \mathrm{E}-180^{\circ}\right)$. The track
TABLE 1. Description of the numerical experiments conducted in this study.

\begin{tabular}{|c|c|}
\hline Expts & Description \\
\hline IE1 & $\begin{array}{l}\text { Control intensity experiment: The intensity } \\
\text { model is run along the observed tracks } \\
\text { of } 713 \text { TCs (1980-2015), and monthly } \\
\text { environmental parameters are used for } \\
\text { each year }\end{array}$ \\
\hline IE2 & $\begin{array}{l}\text { Intensity experiment with the period- } \\
\text { averaged environment: The monthly } \\
\text { environmental parameters are } \\
\text { averaged over 1980-97 and 1998-2015, } \\
\text { respectively; the model is run for the } \\
397 \text { tracks with the environment } \\
\text { averaged over the first period and for } \\
\text { the } 316 \text { tracks with the environment } \\
\text { averaged over the second period }\end{array}$ \\
\hline IE3 & $\begin{array}{l}\text { Intensity experiment for environmental } \\
\text { influence: Same as IE2, but observed } \\
\text { tracks of } 397 \text { tropical cyclones during } \\
1980-97 \text { are also used in the second } \\
\text { period }\end{array}$ \\
\hline IE4 & $\begin{array}{l}\text { Intensity Experiment for environmental } \\
\text { influence: Same as IE3, but observed } \\
\text { tracks of } 316 \text { tropical cyclones during } \\
\text { 1998-2015 are used in both periods }\end{array}$ \\
\hline TE1 & $\begin{array}{l}\text { Control track experiment: The track } \\
\text { experiment is run with the observed } \\
\text { formation location while the monthly } \\
\text { steering flows are averaged over } \\
1980-97 \text { and } 1980-2015\end{array}$ \\
\hline TE2 & $\begin{array}{l}\text { Track experiment for steering change: } \\
\text { Same as TE1, but the observed } \\
\text { formation location during 1980-97 is } \\
\text { also used for 1998-2015 }\end{array}$ \\
\hline TE3 & $\begin{array}{l}\text { Track experiment for steering change: } \\
\text { Same as TE1, but the observed } \\
\text { formation location during 1998-2015 is } \\
\text { also used for 1980-97 }\end{array}$ \\
\hline TE4 & $\begin{array}{l}\text { Track experiment for formation location } \\
\text { change: Same as TE1, but the steering } \\
\text { during } 1980-97 \text { is also used for the } \\
\text { period } 1998-2015\end{array}$ \\
\hline TE5 & $\begin{array}{l}\text { Track experiment for formation location } \\
\text { change: Same as TE1, but the steering } \\
\text { during 1998-2015 is also used for the } \\
\text { period } 1980-97\end{array}$ \\
\hline
\end{tabular}

model takes the translation velocity and formation location as its input.

We conduct five experiments with the track model to distinguish the influence of the change in the environmental steering from that of the formation location (Table 1). The first experiment (TE1) is run with the observed formation location while the monthly steering flows are averaged over 1980-97 and 1998-2015. The purpose of TE1 is to verify the capability of the track model. The other four experiments are used to identify 

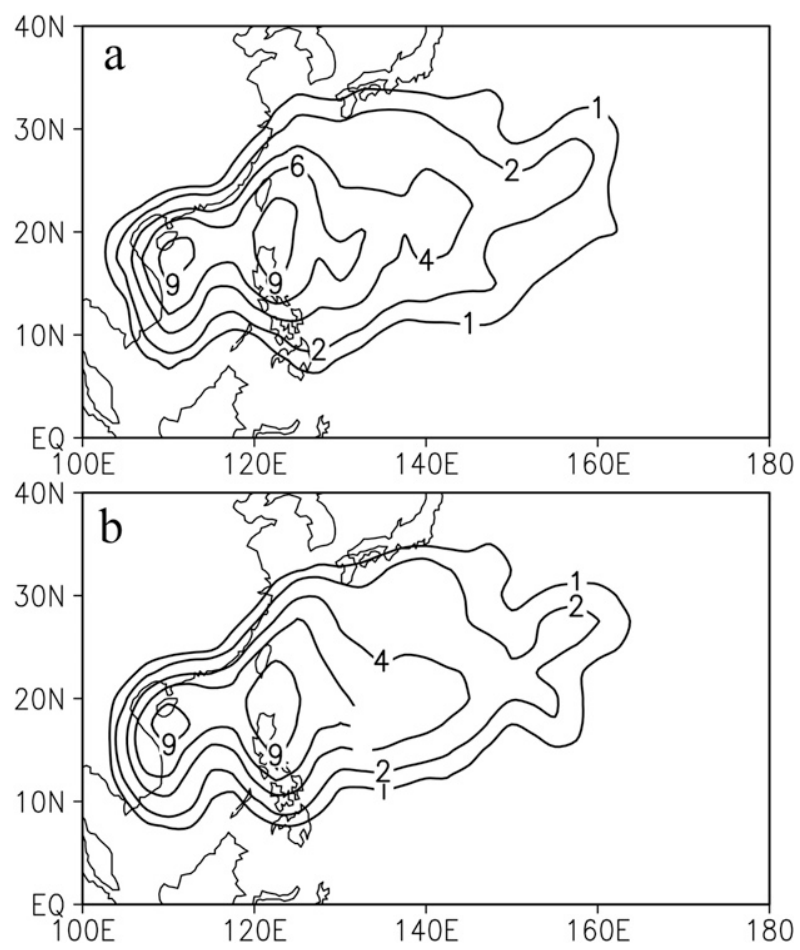

FIG. 1. The (a) observed and (b) simulated spatial distribution of the July-November frequency of LMI occurrence during 19802015 .

the influences of the changes in the TC track and formation location. As indicated in Table 1, the four experiments are similar to TE1 with the only change in the steering flow or formation location. By holding the formation location unchanged during the periods 1980-97 and 1998-2015 in TE2 and TE3, we can estimate the influence of the steering flow change. Similarly, we use the same steering flow in the two periods in TE4 and TE5, we can estimate the influence of the formation location change.

\section{Verification of the coupled intensity model}

The simulated LMI latitudes of TCs in IE1 are first compared with the observation (Fig. 1). The frequency of LMI occurrence is calculated by counting the number of the TCs that reach the LMI in each $2.5^{\circ}$ latitude by $2.5^{\circ}$ longitude grid box, indicating the spatial distribution of LMI occurrence. We can see that the intensity model can well simulate the spatial pattern of the LMI occurrence, which tilts northward with the increase of longitude. Figure 1 suggests that the relative decrease of TCs that take a westward track can lead to the increase of the mean LMI latitude.

Figure 2 displays the comparison of the time series of the July-November mean basinwide LMI between the

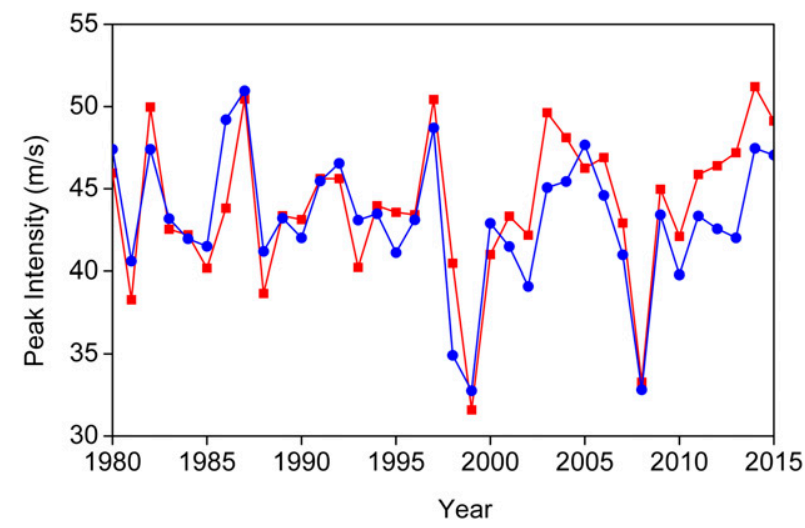

FIG. 2. The observed (red) and simulated (blue) time series of the July-November basinwide mean LMI ( $\left.\mathrm{m} \mathrm{s}^{-1}\right)$ during 1980-2015. The correlation of the two time series is 0.84 .

observation and simulation. The annual mean basinwide LMI is calculated by averaging the LMI of individual TCs in each year. We can see that the evolution of the basinwide LMI from 1980 to 2015 is also well reproduced in IE1, with a correlation coefficient of 0.84 between the simulation and observation, significant at the $95 \%$ confidence level. Note that the basinwide mean LMI shows considerable interannual variations, but with no obvious trend during the period 1980-2015.

In comparison with the observation, Fig. 3 shows the time series of the annual mean LMI latitude during 1980-2015. In observation, the mean LMI latitude exhibits a poleward trend, with a significant linear trend of $0.48^{\circ}(10 \mathrm{yr})^{-1}$. The mean latitude is $20.57^{\circ}$ for the period $1980-97$ and $21.88^{\circ}$ for the period $1998-2015$, with an increase of $1.31^{\circ}$. The simulated poleward trend

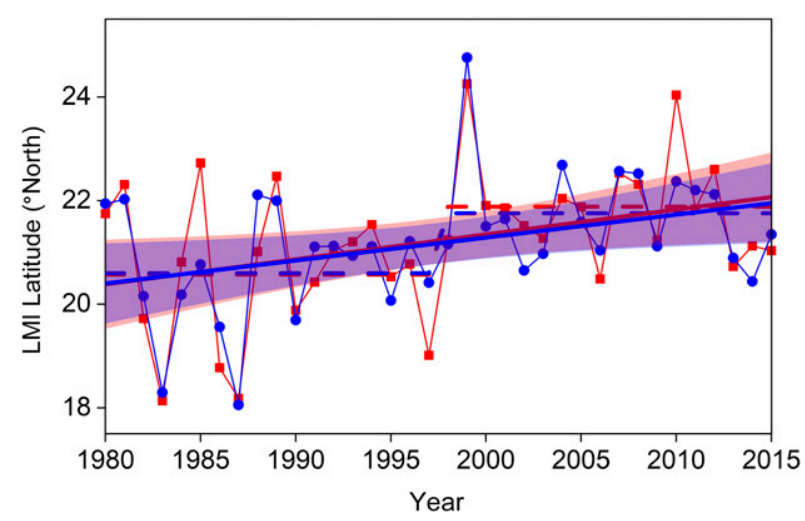

FIG. 3. The observed (red) and simulated (blue) time series of the July-November mean latitude of LMI $\left(^{\circ}\right)$ during 1980-2015, with the trend indicated by the corresponding solid lines and their $95 \%$ two-sided confidence intervals (shaded, purple for the simulation and red for the observation). The dashed lines indicate the means for 1980-97 and 1998-2015. The correlation between the observation and simulation is 0.86 . 
TABLE 2. The observed and simulated LMI mean latitudes $\left({ }^{\circ}\right)$ in IE1 and IE2 during the periods 1980-97 and 1998-2015. The differences at the $95 \%$ confidence level are in boldface type.

\begin{tabular}{lccc}
\hline & $1980-97$ & $1998-2015$ & Diff \\
\hline Obs & 20.57 & 21.88 & $\mathbf{1 . 3 1}$ \\
IE1 & 20.60 & 21.76 & $\mathbf{1 . 1 6}$ \\
IE2 & 20.60 & 21.88 & $\mathbf{1 . 2 8}$
\end{tabular}

is $0.44^{\circ}(10 \mathrm{yr})^{-1}$, comparable to the observation. The simulated mean latitude is $20.6^{\circ}$ for the first period and $21.76^{\circ}$ for the second period, with a latitude difference of $1.16^{\circ}$. The correlation between the observation and simulation is 0.86 during the $36-y r$ period. The observed and simulated trends are statistically significant at the $95 \%$ confidence level. Note that the definition of TCs in this study is somewhat different from that in Sun et al. (2018). Here the storms with maximum wind speed exceeding $17 \mathrm{~m} \mathrm{~s}^{-1}$ is examined, while Sun et al. (2018) included tropical depressions.

In summary, the TC intensity model driven by the large-scale ocean-atmosphere environment can well reproduce the observed spatial pattern of the LMI and the temporal variations of the annual mean LMI latitude. The simulated trend in the annual mean LMI latitude is comparable to the observed one. It is suggested that the observed northward shift of the LMI latitude in the western North Pacific basin is dynamically consistent with the changes in the atmosphere-ocean environment and TC tracks.

\section{Influence of changes in the environmental parameters}

As mentioned above, the environmental parameters in IE2 are averaged over the periods 1980-97 and 19982015 , respectively. The intensity model can simulate the shift of the mean LMI location, which is very close to the observation. The simulated mean latitude of LMI is $20.6^{\circ}$ for the first period and $21.88^{\circ}$ for the second period, with a latitude difference of $1.28^{\circ}$ (Table 2). It agrees well with the observation and the simulation in IE1. Based on the result of IE2, we can use IE3 and IE4 to identify the influence of changes in the environmental parameters and TC tracks.

IE3 and IE4 are similar to IE2, but the effect of the track shift is not considered in the two periods. The effect of the track shift can be estimated by comparing the simulated latitude between IE3 and IE4 during the same period. Table 3 indicates the contributions of the track change and the temporal change of the environmental parameters. Since the track change in IE3 and IE4 is excluded between the two periods, the simulated change
TABLE 3. The simulated mean LMI latitudes $\left(^{\circ}\right)$ in IE3 and IE4, and the influences of the track change and changes in the environmental parameters.

\begin{tabular}{lccc}
\hline \hline & $1980-97$ & $1998-2015$ & Environmental influence \\
\hline IE3 & 20.6 & 20.5 & -0.01 \\
IE4 & 21.85 & 21.88 & 0.03 \\
Track shift & 1.25 & 1.38 & \\
$\quad$ influence & & & \\
\hline
\end{tabular}

of the LMI latitude results only from the temporal changes of the large-scale environmental parameters. It is clearly indicated that the temporal change in the largescale environment contributes little to the change of the mean latitude of the LMI.

By comparing the change of the mean latitude of LMI during the same period in IE3 and IE4, we can see the contribution of the TC track change. As shown in Table 3 , the track change leads to the shifts of $1.25^{\circ}$ and $1.38^{\circ}$ for the large-scale environments in the first and second periods. It is suggested that the difference of the mean latitude of LMI between the two periods is dominantly due to the TC track change.

\section{Influence of the formation location change}

TC tracks can be quantified by the frequency of TC occurrence, which is defined on each grid box to measure how frequently a specific grid box is affected by TCs (Wu et al. 2005). In this study, the grid box covers an area of $2.5^{\circ}$ latitude by $2.5^{\circ}$ longitude and the frequency of TC occurrence is counted at 6-h intervals. The higher the frequency in a given region, the more TC influence in the region. Figure 4a shows the observed change of the frequency of TC occurrence between the periods 1980 97 and 1998-2015 and the corresponding climatologic mean averaged over the period 1980-2015. A salient feature is the decreasing influence south of $20^{\circ} \mathrm{N}$, whereas the TC influence increased in the northwestern part of the basin. Figure 4a indicates that TCs occurred most frequently over northern South China Sea and the adjacent region to the waters southeast of Taiwan. $\mathrm{Wu}$ et al. (2005) suggested that the TC tracks in the western North Pacific basin can be categorized into three prevailing tracks: westward-moving toward the South China Sea, northwestward-moving to influence the coastal region of East Asia, and northeastwardrecurving east of $130^{\circ} \mathrm{E}$. It is suggested that the number of TC tracks that took the westward prevailing track relatively decreased from the period 1980-97 to 1998-2015. Figure 4b shows the simulated difference of the frequency of TC occurrence between the periods 1980-97 and 1998-2015 in TE1. We can see that the 

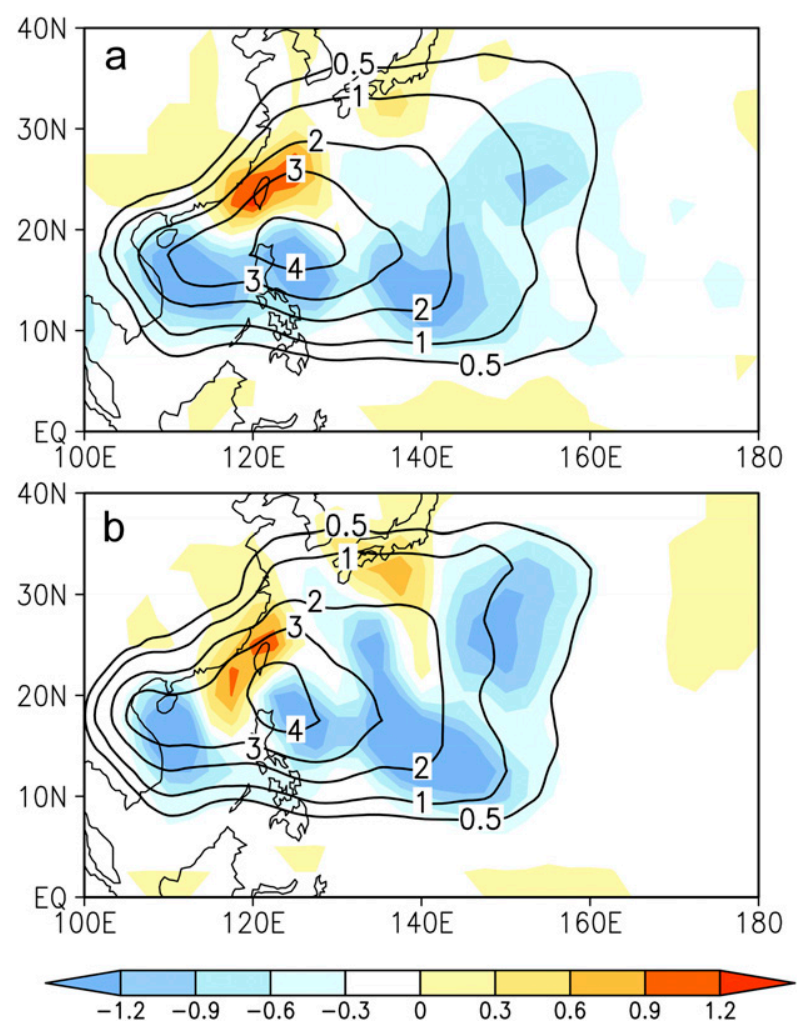

FIG. 4. The differences of the frequency of TC occurrence (shading) between the periods 1980-97 and 1998-2015, and the corresponding climatologic means (contours) averaged over 19802015: (a) the observations and (b) the simulation in TE1.

track model can simulate the major features of the mean spatial distribution and the change of the frequency of TC occurrence, although there are differences in detail.

In the last section, the numerical experiments based on the intensity model demonstrate that the track change plays a dominant role in the northward migration of the mean LMI latitude. Moreover, Fig. 1 suggests that the fewer TCs that take the westward prevailing track, the higher the annual mean LMI latitude. A TC track is basically determined by its formation location and the subsequent movement that is mainly controlled by the environmental steering and the beta drift. $\mathrm{Wu}$ et al. (2015) showed that the annual mean TC genesis longitude has significantly shifted westward since 1979 due to the pronounced westward shift in the tropical upper-tropospheric trough (TUTT). The TC genesis was suppressed in the eastern portion (east of $145^{\circ} \mathrm{E}$ ) of the western North Pacific basin due to the enhanced vertical wind shear associated with the TUTT shift.

Since the previous studies suggest that the northward shift of the mean TC formation location is important to the northward migration of the mean LMI latitude
(Kossin et al. 2014; Kossin et al. 2016; Zhan and Wang 2017; Daloz and Camargo 2018; Song and Klotzbach 2018), four numerical experiments are conducted with the track model (Table 1). Figures $5 \mathrm{a}$ and $5 \mathrm{~b}$ show the contribution of the formation location change, which are derived from TE4 and TE5, respectively. As indicated in Table 1, the difference between TE4 and TE5 is the environmental steering, which are averaged over the periods 1980-97 and 1998-2015, respectively. We can see that the two experiments indicate the very similar influence of the formation location change. The change of the formation location mainly reduced the TC influence over the South China Sea and the west North Pacific. Note that the influence between the Philippines and the island of Taiwan was enhanced.

Figures $5 \mathrm{c}$ and $5 \mathrm{~d}$ show the influence of the change of the environmental steering. We can see that the change of the environmental steering enhanced the TC activity north of $20^{\circ} \mathrm{N}$ and west of $140^{\circ} \mathrm{E}$ and reduced the influence south of $20^{\circ} \mathrm{N}$. The changes of the environmental steering are also plotted in the two figures. In the western portion of the basin, where most TCs reach their LMI, there are a cyclonic pattern in the change of the environmental steering. The enhanced eastward steering in the South China Sea decreased the influence of the westward-moving TCs, and relatively more TCs took the northwestward-moving track. The enhanced northward steering is further favorable for the northward movement of the TC. Although the formation location change leads to relatively more TCs to take the northwestwardmoving track, Fig. 5 suggests that the steering change is more effective than the formation location change since the latter also leads to considerable decrease in TC activity over the western North Pacific. Therefore, we argue that the northward shift of the mean LMI latitude in the western North Pacific results mainly from the change of the environmental steering.

To further demonstrate the dominant role of the change in the environmental steering, Fig. 6a shows the comparison of the count of TC formation on different latitude bands between the periods 1980-97 and 19982015. Consistent with the shift of the formation location, the count of TC formation decreased south of $20^{\circ} \mathrm{N}$ during the second period, but slightly increased beyond $20^{\circ} \mathrm{N}$. Figure $6 \mathrm{~b}$ shows the comparison of the mean LMI latitude for tropical cyclones that formed in different latitude bands between the periods 1980-97 and 19982015. It is clear that the increased formation of the tropical cyclones beyond $20^{\circ} \mathrm{N}$ did not lead to a northward shift in the mean LMI latitude. This further suggests that the change of the environmental steering play a dominant role in the northward shift of the mean LMI latitude. 

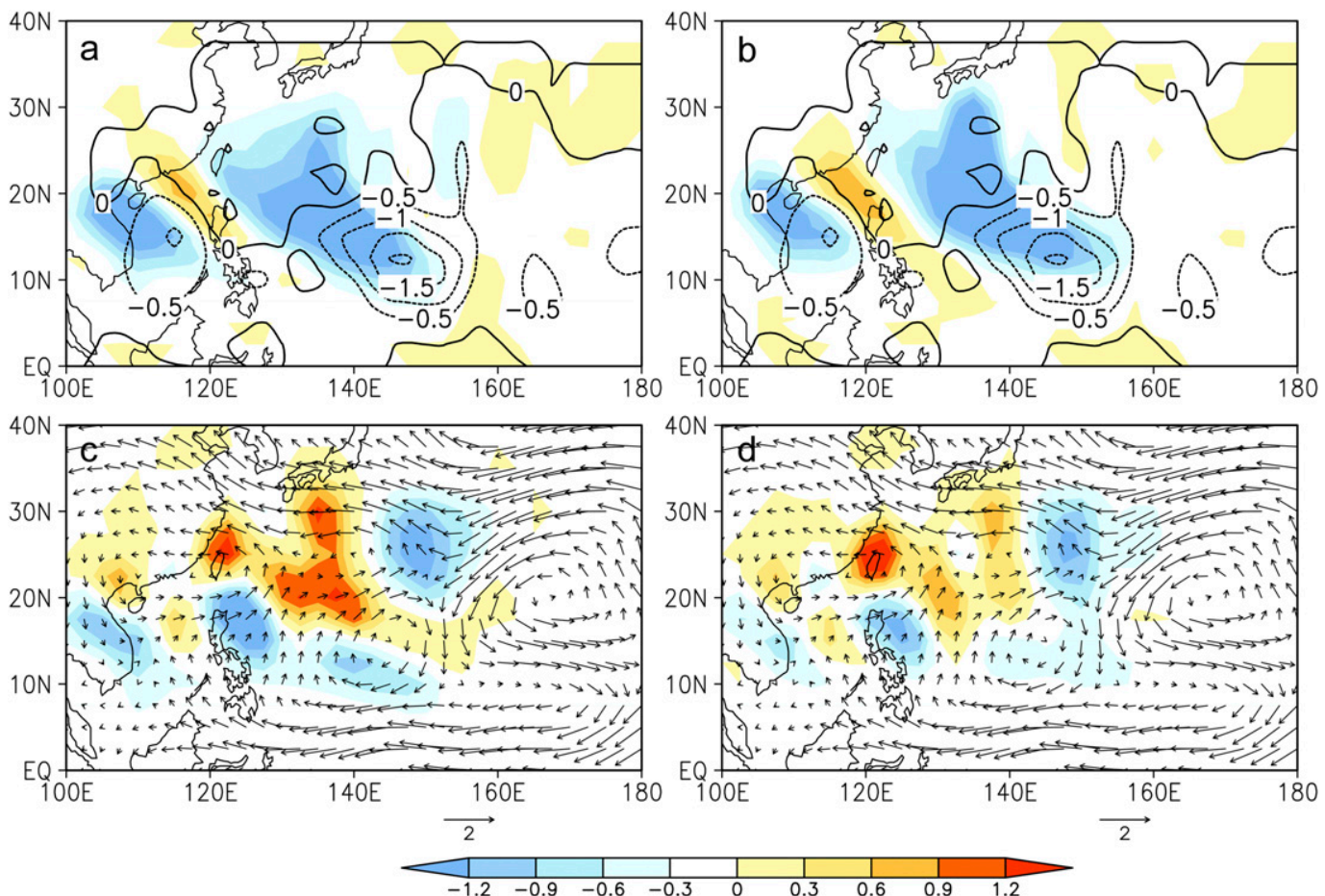

FIG. 5. The contributions [(a),(b) on the basis of the results of TE4 and TE5, and (c),(d) derived from TE2 and TE3] of the change of TC formation location [shading in (a) and (b)] and the change of the steering flow [shading in (c) and (d)] to the change of the frequency of tropical cyclone occurrence. In (a) and (b) the contours indicate the change of the formation location, and in (c) and (d) the vectors are the differences of steering flows between 198097 and 1998-2015.

Previous studies detected the similar track shift since the late 1970s (Wu et al. 2005; Wang et al. 2011; Zhao and $\mathrm{Wu} 2014$ ). Such a track shift pattern is qualitatively similar to that found under future climate change forcing experiments by selected subsets of phase 3 and phase 5 of the Coupled Model Intercomparison Project (CMIP3 and CMIP5; Wang et al. 2011; Wang and Wu 2015). However, since the projected changes are only examined in the selected subsets of CMIP3 and CMIP5 experiments, caution should be taken to contribute the track changes to global warming. In addition, our study covers the period 1980-2015 and the relatively short period can include considerable influences of interdecadal to multidecadal oscillations. Song and Klotzbach (2018) identified the periods 1978-97 and 1998-2016 as the negative and positive phases, respectively, of the interdecadal Pacific oscillation (IPO), and they found that TCs form more northwest in the IPO negative phase and more southeast in the IPO positive phase. They argued that the formation location shift is associated with the interaction between the IPO and El Niño-Southern Oscillation (ENSO). More La Niña events occur in the negative IPO phase, and more El Niño events occur in the positive IPO phase. We can see that the two periods discussed in this study correspond to the negative and positive phases of the IPO, suggesting the influence of the IPO.

\section{Conclusions}

The annual mean latitude of TC LMI over the WNP basin has significantly shifted northward since the 1980s. In this study, the contributions of changes in the environmental parameters and the track change are quantified to understand the mechanism responsible for the poleward shift of the mean LMI latitude. Using a TC intensity model, we first demonstrate that the observed trend of the mean LMI latitude in the JTWC dataset during the period 1980-2015 can be dynamically simulated by running the intensity model along the observed TC tracks, suggesting that the observed poleward trend in the mean latitude of LMI is physically consistent with changes in the large-scale ocean-atmosphere environment and TC tracks.

Our numerical experiments further demonstrate that the temporal change in the environmental parameters (SST, OFT, VWS, and MLD) has little influence on the shift of the mean LMI latitude. In fact, we also examined 

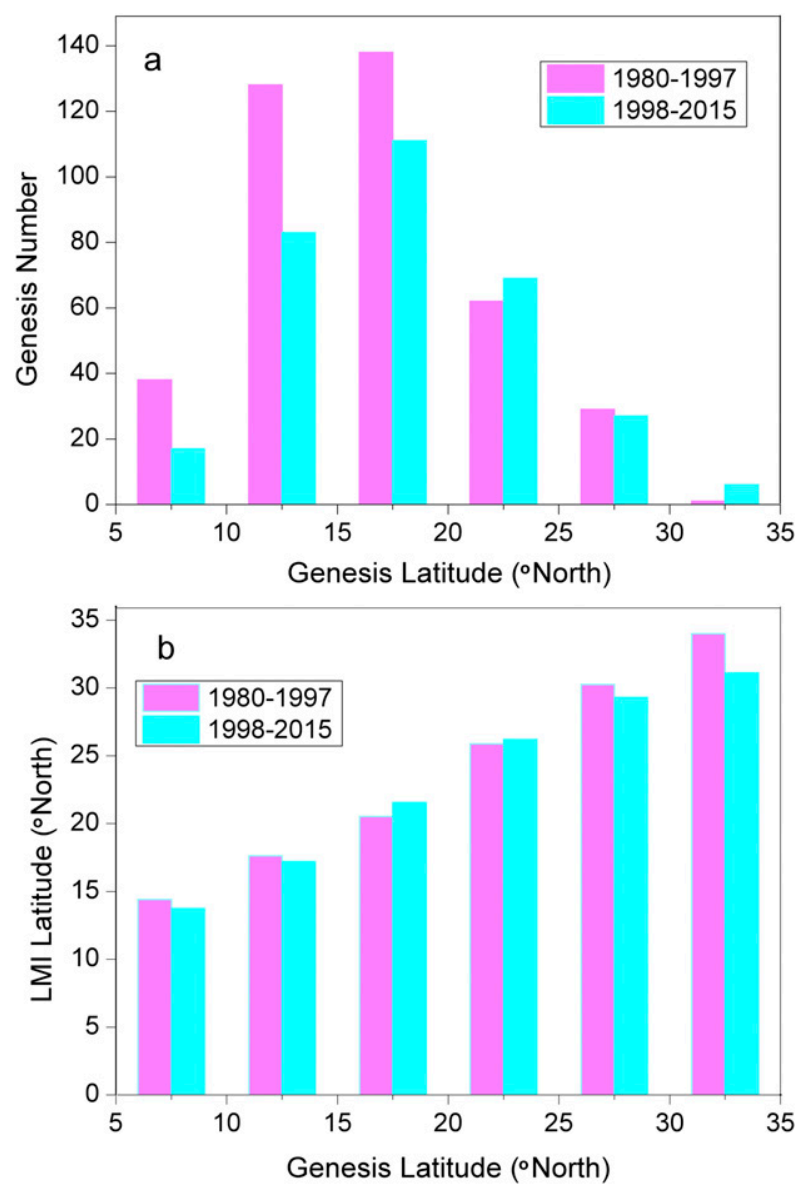

FIG. 6. (a) The counts of TC formation on different latitude bands and (b) the mean LMI latitude for TCs that formed in different latitude bands during the periods 1980-97 and 1998-2015.

the contributions of each environmental parameter, none of their temporal has noticeable effect on the shift of the mean LMI latitude. However, it is found that the poleward migration of the mean LMI latitude resulted mainly from the TC track shift, which includes the changes of TC formation location and environmental steering. A series of numerical experiments with a TC track model show that the TC track change results primarily from the change in the large-scale steering flow. The change of the environmental steering made relatively fewer TCs take the westward-moving track, leading to the poleward shift of the annual mean LMI latitude.

Acknowledgments. The authors thank Prof. Kerry A. Emanuel of Massachusetts Institute of Technology for allowing us to use his tropical cyclone intensity model and Dr. Thomas R. Knutson of NOAA/Geophysical Fluid Dynamics Laboratory/for his invaluable comments. This research was jointly supported by the
National Basic Research Program of China (2015CB452803) and the National Natural Science Foundation of China (41730961, 41675051, and 41705060). The tropical cyclone dataset is the best-track data from the JTWC. The following reanalysis datasets are used: NCEPNCAR, ERA-Interim, JRA-55, MERRA, NCEP-DOE, and CFSR. The SST is from the ERSST (version 4) dataset, and the ocean mixed layer depth is from the NCEP GODAS dataset.

\section{REFERENCES}

Bender, M., and I. Ginis, 2000: Real-case simulations of hurricaneocean interaction using a high resolution coupled model: Effects on hurricane intensity. Mon. Wea. Rev., 128, 917-946, https:// doi.org/10.1175/1520-0493(2000)128<0917:RCSOHO >2.0.CO;2.

Daloz, A. S., and S. J. Camargo, 2018: Is the poleward migration of tropical cyclone maximum intensity associated with a poleward migration of tropical cyclone genesis? Climate Dyn., 50, 705-715, https://doi.org/10.1007/S00382-017-3636-7.

Dee, D., and Coauthors, 2011: The ERA-Interim reanalysis: Configuration and performance of the data assimilation system. Quart. J. Roy. Meteor. Soc., 137, 553-597, https://doi.org/ 10.1002/qj.828.

Emanuel, K., 1987: The dependence of hurricane intensity on climate. Nature, 326, 483-485, https://doi.org/10.1038/326483a0.

_ 1999: Thermodynamic control of hurricane intensity. Nature, 401, 665-669, https://doi.org/10.1038/44326.

— C. DesAutels, C. Holloway, and R. Korty, 2004: Environmental control of tropical cyclone intensity. J. Atmos. Sci., 61, 843-858, https://doi.org/10.1175/1520-0469(2004)061<0843: ECOTCI $>2.0 . \mathrm{CO} ; 2$.

_ , R. Sundararajan, and J. Williams, 2008: Hurricanes and global warming: Results from downscaling IPCC AR4 simulations. Bull. Amer. Meteor. Soc., 89, 347-367, https://doi.org/ 10.1175/BAMS-89-3-347.

—, S. Solomon, D. Folini, S. Davis, and C. Cagnazzo, 2013: Influence of tropical tropopause layer cooling on Atlantic hurricane activity. J. Climate, 26, 2288-2301, https://doi.org/ 10.1175/JCLI-D-12-00242.1.

Frank, W., and E. Ritchie, 2001: Effects of vertical wind shear on the intensity and structure of numerically simulated hurricanes. Mon. Wea. Rev., 129, 2249-2269, https://doi.org/10.1175/15200493(2001)129<2249:EOVWSO>2.0.CO;2.

Gray, W., 1968: Global view of the origin of tropical disturbances and storms. Mon. Wea. Rev., 96, 669-700, https://doi.org/10.1175/ 1520-0493(1968)096<0669:GVOTOO >2.0.CO;2.

Huang, B., and Coauthors, 2015: Extended Reconstructed Sea Surface Temperature version 4 (ERSST.v4): Part I. Upgrades and intercomparisons. J. Climate, 28, 911-930, https://doi.org/ 10.1175/JCLI-D-14-00006.1.

Kalnay, E., and Coauthors, 1996: The NCEP/NCAR 40-Year Reanalysis Project. Bull. Amer. Meteor. Soc., 77, 437-471, https:// doi.org/10.1175/1520-0477(1996)077<0437:TNYRP>2.0.CO;2.

Kamahori, H., N. Yamazaki, N. Mannoji, and K. Takahashi, 2006: Variability in intense cyclone days in the western North Pacific. SOLA, 2, 104-107, https://doi.org/10.2151/SOLA.2006-027.

Kanamitsu, M., W. Ebisuzaki, J. Woollen, S.-K. Yang, J. J. Hnilo, M. Fiorino, and G. L. Potter, 2002: NCEP-DOE AMIP-II Reanalysis (R-2). Bull. Amer. Meteor. Soc., 83, 1631-1643, https:// doi.org/10.1175/BAMS-83-11-1631. 
Klotzbach, P., and C. Landsea, 2015: Extremely intense hurricanes: Revisiting Webster et al. (2005) after 10 years. J. Climate, 28, 7621-7629, https://doi.org/10.1175/JCLI-D-15-0188.1.

Kobayashi, S., and Coauthors, 2015: The JRA-55 Reanalysis: General specifications and basic characteristics. J. Meteor. Soc. Japan, 93, 5-48, https://doi.org/10.2151/jmsj.2015-001.

Kossin, J., T. Olander, and K. Knapp, 2013: Trend analysis with a new global record of tropical cyclone intensity. J. Climate, 26, 9960-9976, https://doi.org/10.1175/JCLI-D-13-00262.1.

_ K. Emanuel, and G. Vecchi, 2014: The poleward migration of the location of tropical cyclone maximum intensity. Nature, 509, 349-352, https://doi.org/10.1038/nature13278.

,$- \ldots$, and S. Camargo, 2016: Past and projected changes in western North Pacific tropical cyclone exposure. J. Climate, 29, 5725-5739, https://doi.org/10.1175/JCLI-D-16-0076.1.

Landsea, C., B. Harper, K. Hoarau, and J. Knaff, 2006: Can we detect trends in extreme tropical cyclones? Science, 313, 452454, https://doi.org/10.1126/science.1128448.

Moon, I.-J., S.-H. Kim, P. Klotzbach, and J. C. L. Chan, 2015: Roles of interbasin frequency changes in the poleward shifts of the maximum intensity location of tropical cyclones. Environ. Res. Lett., 10, 104004, https://doi.org/10.1088/1748-9326/10/10/104004.

Rienecker, M., and Coauthors, 2011: MERRA: NASA's ModernEra Retrospective Analysis for Research and Applications. J. Climate, 24, 3624-3648, https://doi.org/10.1175/JCLI-D-1100015.1

Saha, S., and Coauthors, 2006: The NCEP Climate Forecast System. J. Climate, 19, 3483-3517, https://doi.org/10.1175/JCLI3812.1.

— , and Coauthors, 2010: The NCEP Climate Forecast System Reanalysis. Bull. Amer. Meteor. Soc., 91, 1015-1057, https:// doi.org/10.1175/2010BAMS3001.1.

Shay, L., G. Goni, J. Goni, and P. Black, 2000: Role of a warm ocean feature on Hurricane Opal. Mon. Wea. Rev., 128, 1366-1383, https://doi.org/10.1175/1520-0493(2000)128<1366:EOAWOF $>2$. $0 . \mathrm{CO} ; 2$.

Song, J., and P. J. Klotzbach, 2018: What has controlled the poleward migration of annual averaged location of tropical cyclone lifetime maximum intensity over the western North Pacific since 1961? Geophys. Res. Lett., 45, 1148-1156, https:// doi.org/10.1002/2017GL076883.

_- Y. Wang, and L. Wu, 2010: Trend discrepancies among three best track data sets of western North Pacific tropical cyclones.
J. Geophys. Res., 115, D12128, https://doi.org/10.1029/ 2009JD013058.

Sun, Y., and Coauthors, 2018: A recent reversal in the poleward shift of western North Pacific tropical cyclones. Geophys. Res. Lett., 45, 9944-9952, https://doi.org/10.1029/2018GL079686.

Wang, C., and L. Wu, 2015: Influence of future tropical cyclone track changes on their basin-wide intensity over the western North Pacific: Downscaled CMIP5 projections. $A d v$. Atmos. Sci., 32, 613-623, https://doi.org/10.1007/s00376014-4105-4.

Wang, R., L. Wu, and C. Wang, 2011: Typhoon track changes associated with global warming. J. Climate, 24, 3748-3752, https://doi.org/10.1175/JCLI-D-11-00074.1.

Wu, L., and B. Wang, 2004: Assessing impacts of global warming on tropical cyclone tracks. J. Climate, 17, 1686-1698, https:// doi.org/10.1175/1520-0442(2004)017<1686:AIOGWO>2. $0 . \mathrm{CO} ; 2$.

— , and H. Zhao, 2012: Dynamically derived tropical cyclone intensity changes over the western North Pacific. J. Climate, 25, 89-98, https://doi.org/10.1175/2011JCLI4139.1.

— B. Wang, and S. Braun, 2005: Impacts of air-sea interaction on tropical cyclone track and intensity. Mon. Wea. Rev., 133, 3299-3314, https://doi.org/10.1175/MWR3030.1.

, C. Wang, and B. Wang, 2015: Westward shift of western North Pacific tropical cyclogenesis. Geophys. Res. Lett., 42, 1537-1542, https://doi.org/10.1002/2015GL063450.

, R. Wang, and X. Feng, 2018: Dominant role of the ocean mixed layer depth in the increased proportion of intense typhoons during 1980-2015. Earth's Future, 6, https://doi.org/ 10.1029/2018EF000973.

Wu, M., K. Yeung, and W. Chang, 2006: Trends in western North Pacific tropical cyclone intensity. Eos, Trans. Amer. Geophys. Union, 87, 537-538, https://doi.org/10.1029/2006EO480001.

Zhan, R., and Y. Wang, 2017: Weak tropical cyclones dominate the poleward migration of the annual mean location of lifetime maximum intensity of northwest Pacific tropical cyclones since 1980. J. Climate, 30, 6873-6882, https://doi.org/10.1175/JCLID-17-0019.1.

Zhao, H., and L. Wu, 2014: Inter-decadal shift of the prevailing tropical cyclone tracks over the western North Pacific and its mechanism study. Meteor. Atmos. Phys., 125, 89-101, https:// doi.org/10.1007/s00703-014-0322-8. 